\title{
Corrosion Inhibition of Nickel in Sulfuric Acid Using Tween Surfactants
}

\author{
M. Abdallah, A.Y. El-Etre* \\ Chemistry Department, Faculty of Science, Benha University, Benha, Egypt
}

Received 3 December 2002; accepted in revised form 1 April 2003

\begin{abstract}
Four commercial non-ionic surfactant compounds, namely tween 80, 60, 40 and 20, were tested as inhibitors for corrosion of nickel in $1.0 \mathrm{M} \mathrm{H}_{2} \mathrm{SO}_{4}$ solution. Weight loss measurements, potentiostatic polarization and cyclic voltammetry techniques were used in this study. It was found that all the four used compounds act as good inhibitors for acid corrosion of nickel. The inhibition efficiencies obtained by the three techniques were almost the same, and increase with increasing the hydrocarbon chain length, the presence of a double bond in the chemical structure of the surfactant and with increasing the surfactant concentration. The polarization studies show that tween compounds act as mixed inhibitors. The inhibition action of these surfactants is interpreted in view of their adsorption on the metal surface making a barrier to mass and charge transfer. It was found that the adsorption of only tween 20 and 40 follows Langmuir adsorption isotherm. The values of free energy of adsorption for them were calculated. It was found that the adsorption process is spontaneous and increases, for different surfactants, in the same direction as inhibition efficiency. The cyclic voltammetry shows that there is only one anodic peak corresponding to the dissolution reaction of nickel electrode. The current of this dissolution peak was used also for corrosion rate measurements and in evaluation of inhibition efficiencies of the used compounds.
\end{abstract}

Keywords: nickel, corrosion inhibition, tween, surfactant.

\section{Introduction}

Nickel is one of the most important metals and is used in a large number of applications. The pure nickel has a good corrosion resistance and is frequently used as a protective coat for other metals and alloys. For the same reason, nickel is used as alloying element with other metals. Nickel based alloys show a

\footnotetext{
*Corresponding author. E-mail address: aliyousry@hotmail.com
} 
considerable resistance against different types of corrosion. Even the addition of small quantity of nickel to an alloy improves its corrosion resistance character. The corrosion resistance of nickel is due to the formation of a passive film on its surface upon exposure to the corrosive media. Nevertheless, nickel could be attacked by acidic media in a considerable rate. Many works were conducted to study the passivation of nickel in different acidic solutions [1-5]. It was reported that the passive film formed on nickel surface in low concentrations of sulfuric acid is $\mathrm{NiOOH}$ [3] or $\mathrm{NiO}$ and $\mathrm{Ni}_{2} \mathrm{O}_{3}$ [4]. On the other hand, $\beta-\mathrm{NiSO}_{4} \cdot 6 \mathrm{H}_{2} \mathrm{O}$ was suggested as the passive compound formed in very high concentrations of sulfuric acid [5]. However, the obtained results showed that nickel establishes a kind of passivity in acidic solutions in which the corrosion current, in the passive potential range, is somewhat higher than those recorded by other passive metals. Because nickel is frequently used in contact with acidic solutions, its corrosion rate must be controlled. One of the useful methods of controlling the corrosion process is the addition of corrosion inhibitor.

Many researches were published in the literature concerning the usage of inhibitors for nickel corrosion in acidic solutions [6-12]. Most of the tested inhibitors are organic compounds containing sulfur or nitrogen in their chemical structures. It was found that this kind of compounds is chemically adsorbed on the nickel surface forming a barrier for mass and charge transfer and consequently decreasing the rate of corrosion. Unfortunately, most of these compounds are harmful for human and environment. Therefore, additional work should be conducted to find safe and cheap corrosion inhibitors for nickel in acidic solutions. This work is devoted to test a series of tween surfactants as inhibitors for nickel corrosion in sulfuric acid solution. Tween compounds can be easily synthesized from relatively cheap raw materials. In addition, tween compounds are non toxic and have surface active property. Weight loss measurements, cyclic voltammetry and polarization techniques were used in the study to evaluate the inhibition efficiency of the tested tween compounds. 


\section{Experimental}

Coupons of pure nickel with dimensions of $1 \times 2 \times 0.2 \mathrm{~cm}$ were used in weight loss experiments. For potentiostatic polarization technique, a cylindrical rod of nickel embedded in araldite with an exposed bottom area of $0.5 \mathrm{~cm}^{2}$ was used. Before each experiment, the electrode was polished to a mirror finish with different grades of emery papers, degreased with acetone and finally rinsed with distilled water. BDH grade sulfuric acid was used for the preparation of the test solutions.

Weight loss measurements were carried out by the same method as described elsewhere [13]. Each of the nickel sheets was immersed, for 6.0 hours, in $50 \mathrm{~mL}$ of $1.0 \mathrm{M} \mathrm{H}_{2} \mathrm{SO}_{4}$ solutions containing different concentrations of tween compounds, at $25( \pm 1){ }^{\circ} \mathrm{C}$. A three electrodes cell, with saturated calomel reference electrode (SCE) and platinum foil counter electrode was used in polarization experiments. Both potentiostatic polarization and cyclic volammetry technique were carried out using a PS remot potentiostat with zum PS6 software for calculation of electrochemical parameters.

The used tween surfactants are organic compounds which have surface active properties and commercially available with relatively low price. Four different tween compounds are used in the present study, namely, tween 20, 40, 60 and 80. Tween compounds are basically polyoxyethelene sorbitan combined with different fatty acids. The number associated with the tween name determines the predominant fatty acid contained in the tween structure. Thus, for tween 20, 40, 60 and 80, the acids are, respectively, monolaurate, monopalmitate, monostearate and monooleate.

\section{Results and Discussion}

\section{Weight loss measurements}

The losses of weight of nickel sheets due to their immersion in solutions of $1.0 \mathrm{M}$ $\mathrm{H}_{2} \mathrm{SO}_{4}$ containing different concentrations of tween compounds were measured. It was found that the addition of any of the used four tween compounds lowers the weight loss of the nickel sheet than its value in the free acid solution. This 
result indicates that the four tween compounds act as inhibitors for nickel corrosion in sulfuric acid solution. The inhibitive action of tween compounds could be attributed to the adsorption of their molecules on the nickel surface, forming a barrier between the bar metal and the corrosive environment. The surface activity of tween compounds as well as the presence of function groups, such as carbonyl group, in their structures facilitates such adsorption. The surfactant molecules adsorb on the metal surface via their function groups, while their hydrocarbon chains are oriented toward the aqueous solution. Since these hydrocarbon chains are hydrophobic in nature, they repel the aqueous aggressive anions away from the metal surface and therefore inhibit the corrosion reaction. The inhibition efficiencies (IE\%) of different concentrations of the four tween compounds are given in Table (1). The inhibition efficiency was calculated using the following equation:

$$
\mathrm{IE} \%=\left[\left(\mathrm{w}_{\mathrm{f}}-\mathrm{w}_{\mathrm{i}}\right) / \mathrm{w}_{\mathrm{f}}\right] \times 100
$$

where $\mathrm{w}_{\mathrm{f}}$ and $\mathrm{w}_{\mathrm{i}}$ are weight loss of nickel coupon in free and inhibited acid, respectively.

Table 1. Dependence of IE of tween compounds on their concentrations as revealed from weight loss measurements.

\begin{tabular}{ccccc}
\hline \multirow{2}{*}{ Conc./ppm } & \multicolumn{5}{c}{ IE\% } \\
\cline { 2 - 5 } & T 20 & T 40 & T 60 & T 80 \\
\hline 50 & 49.52 & 55.95 & 85.51 & 92.06 \\
100 & 63.33 & 68.67 & 91.72 & 93.82 \\
200 & 78.52 & 82.98 & 92.53 & 96.21 \\
400 & 88.16 & 89.54 & 94.36 & 98.02 \\
600 & 89.85 & 92.37 & 95.06 & 98.68 \\
\hline
\end{tabular}

Inspection of Table 1 reveals that the inhibition efficiency increases as the inhibitor concentration is increased. This behavior could be attributed to the increase of the metal surface area covered by the adsorbed inhibitor molecules with the increasing inhibitor concentration. Furthermore, data in Table 1 show 
that the extent of inhibition of different tween compounds depends on their structures. The inhibition efficiency increases in the following order:

$$
\text { T } 20<\text { T } 40<\text { T } 60<\text { T } 80
$$

This sequence reflects the effect of type of the fatty acid included in the tween formula, on their inhibitive action, since all tween compounds are mainly polyoxyethylene sorbitane combined with alkyl chain of different fatty acids which determine the tween number. Now, one can rewrite the above sequence, according the alkyl chain, as following:

$$
\text { Laurate }\left(\mathrm{C}_{12}\right)<\text { palmitate }\left(\mathrm{C}_{16}\right)<\text { stearate }\left(\mathrm{C}_{18}\right)<\text { oleate }\left(\mathrm{C}_{18}\right)
$$

This new sequence illustrates the effects of both hydrocarbon length and presence of a double bond in the inhibitor structure. Thus, for the first three compounds, the inhibition efficiency increases as the number of carbon atoms in the alkyl chain increases. On the other hand, for the last two compounds, which contain the same number of carbon atoms, the presence of the double bond in the latter made it superior to the former.

\section{Potentiostatic polarization}

Fig. 1 represents the anodic and cathodic polarization curves of nickel electrode, in $1.0 \mathrm{M} \mathrm{H}_{2} \mathrm{SO}_{4}$ solutions containing different concentrations of tween 80 compound. Similar curves were also obtained for the other three tween compounds. Inspection of Fig. 1 reveals that, both anodic and cathodic polarization curves are shifted to less current density values in the presence of tween compound. This behavior suggests the inhibitive action of the tween compounds. The extent of the shift in current density increases with increasing of tween compounds concentration.

The values of corrosion current density $\left(\mathrm{i}_{\text {corr }}\right)$, corrosion potential $\left(\mathrm{E}_{\text {corr }}\right)$, anodic Tafel constant $\left(\beta_{\mathrm{a}}\right)$ and cathodic Tafel constant $\left(\beta_{\mathrm{c}}\right)$, excluded from polarization curves are given in Table 2. Inspection of Table 2 reveals that the corrosion potential of nickel in the acid solution is largely shifted to less negative values (noble direction) upon addition of tween compounds. The magnitude of this shift 
increases with increasing of the associated number of tweens and with increasing of the additive concentration.

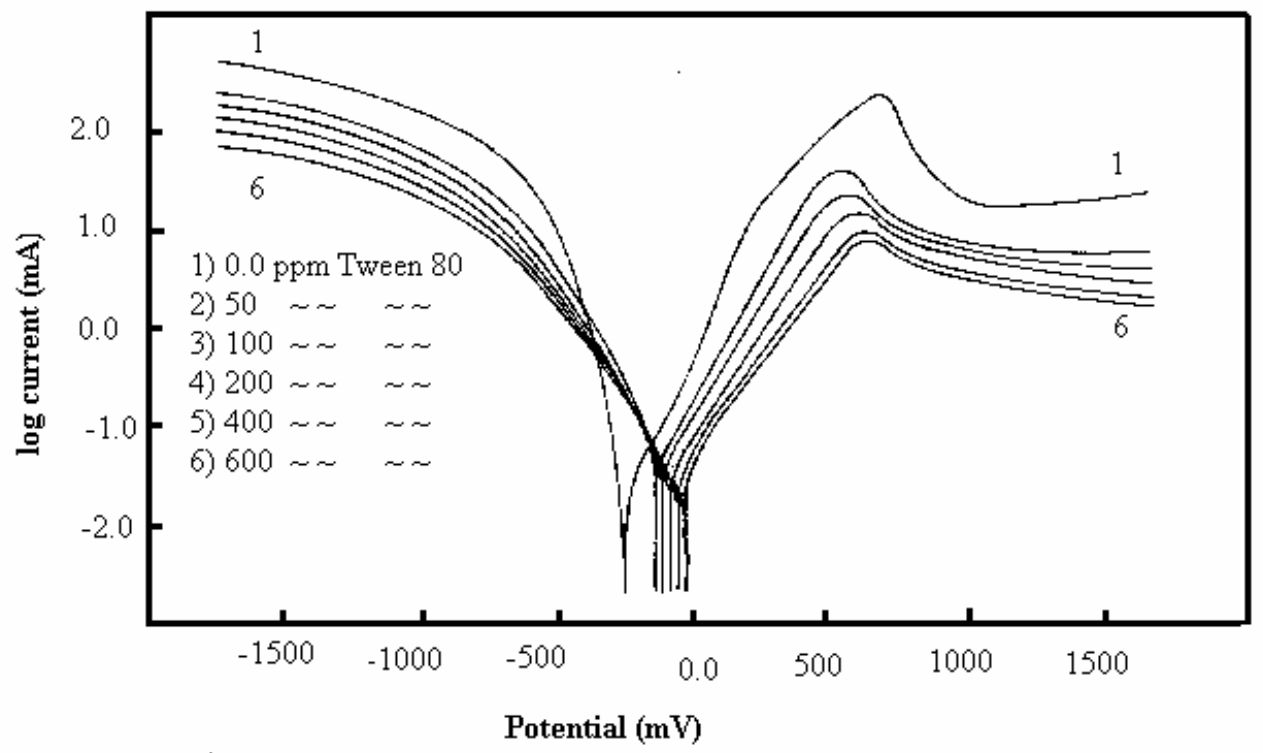

Figure 1. Polarization curves of nickel in $1.0 \mathrm{M} \mathrm{H}_{2} \mathrm{SO}_{4}$ solutions containing different concentrations of tween 80 .

On the other hand, the corrosion current density is greatly reduced upon addition of any of the four tween compounds. These results suggest the inhibitive effects of the tested compounds. The data in Table 2 reveal that the values of inhibition efficiency obtained by polarization technique are comparable to those obtained by weight loss measurements. The inhibition efficiency increases with increasing tween concentration. The inhibition efficiency depends on the type of tween compounds. It could be recognized in Table 2 that the inhibition efficiency of the four tween compounds increases in the following order:

$$
\mathrm{T} 20<\mathrm{T} 40<\mathrm{T} 60<\mathrm{T} 80
$$

It is of interest to note that this sequence is the same like that obtained by weight loss measurements. Further inspection of Table 2 reveals that the addition of increasing concentrations of tween compounds decreases both the anodic and cathodic Tafel constants. This result indicates that the non-ionic surfactants act as mixed inhibitors. This means that the surfactant molecules are adsorbed on both the anodic and cathodic sites resulting in an inhibition of both anodic dissolution and cathodic reduction reactions. The greater the metal surface area occupied by 
adsorbed molecules, the higher the inhibition efficiency. A parameter $(\theta)$ which represents the fraction of the metal surface covered by adsorbed molecules is calculated using the following equation:

$$
\theta=\left[\left(\mathrm{I}_{\mathrm{f}}-\mathrm{I}_{\mathrm{i}}\right) / \mathrm{I}_{\mathrm{f}}\right]
$$

where $I_{f}$ and $I_{i}$ are the corrosion currents in free and inhibited acid solutions, respectively. The values of $\theta$ corresponding to different concentrations of tween compounds are given in Table 2.

Table 2. Electrochemical parameters of nickel corrosion in free and inhibited $1.0 \mathrm{M}$ $\mathrm{H}_{2} \mathrm{SO}_{4}$ solutions.

\begin{tabular}{ccccccc}
\hline $\begin{array}{c}\text { Inh. conc./ } \\
\text { ppm }\end{array}$ & $\begin{array}{c}\mathrm{E}_{\text {corr }} / \\
\mathrm{mV}\end{array}$ & $\begin{array}{c}\mathrm{I}_{\text {corr }} / \\
\left(\mathrm{mA} / \mathrm{cm}^{2}\right)\end{array}$ & $\beta \mathrm{a}$ & $-\beta \mathrm{c}$ & $\mathrm{IE} \%$ & $\theta$ \\
\hline 0.0 T20 & -280 & 11.46 & 285 & 638 & - & - \\
50 & -80 & 6.197 & 170 & 415 & 45.4 & 0.454 \\
100 & -68 & 4.2975 & 172 & 405 & 62.5 & 0.625 \\
200 & -54 & 2.647 & 158 & 385 & 76.9 & 0.769 \\
400 & -40 & 1.192 & 161 & 380 & 89.6 & 0.896 \\
600 & -25 & 1.111 & 155 & 368 & 90.3 & 0.903 \\
\hline 0.0 T 40 & -280 & 11.46 & 285 & 638 & - & - \\
50 & -95 & 5.432 & 165 & 448 & 52.6 & 0.526 \\
100 & -83 & 3.827 & 155 & 435 & 66.6 & 0.666 \\
200 & -74 & 2.292 & 162 & 422 & 80 & 0.8 \\
400 & -62 & 1.317 & 164 & 410 & 88.5 & 0.885 \\
600 & -51 & 0.962 & 161 & 390 & 91.6 & 0.916 \\
\hline 0.0 T60 & -280 & 11.46 & 285 & 638 & - & - \\
50 & -102 & 1.845 & 155 & 420 & 83.9 & 0.839 \\
100 & -95 & 1.249 & 158 & 380 & 89.1 & 0.891 \\
200 & -82 & 1.077 & 168 & 372 & 90.6 & 0.906 \\
400 & -68 & 0.825 & 170 & 370 & 92.8 & 0.928 \\
600 & -54 & 0.687 & 165 & 365 & 94 & 0.94 \\
\hline 0.0 T 80 & -280 & 11.46 & 285 & 638 & - & - \\
50 & -112 & 1.012 & 146 & 431 & 91.1 & 0.911 \\
100 & -105 & 0.756 & 158 & 377 & 93.4 & 0.934 \\
200 & -95 & 0.446 & 153 & 343 & 96.1 & 0.961 \\
400 & -82 & 0.309 & 161 & 368 & 97.3 & 0.973 \\
600 & -69 & 0.286 & 161 & 320 & 97.5 & 0.975 \\
\hline & & & & & &
\end{tabular}

Plotting of $\log \theta / 1-\theta$ versus logarithm of tween concentration give straight lines with slopes very close to unity for the compounds T20 and T40, but the values are deviated from unity for T60 and T80 (Fig. 2). These results suggest that the 
adsorption of the first two tween compounds on nickel surface follows Langmuir adsorption isotherm. This isotherm postulates that there is no kind of interaction forces that could arise between the molecules adsorbed at the metal surface. Thus, the free energy of adsorption of the molecule is independent on the value of $\theta$.

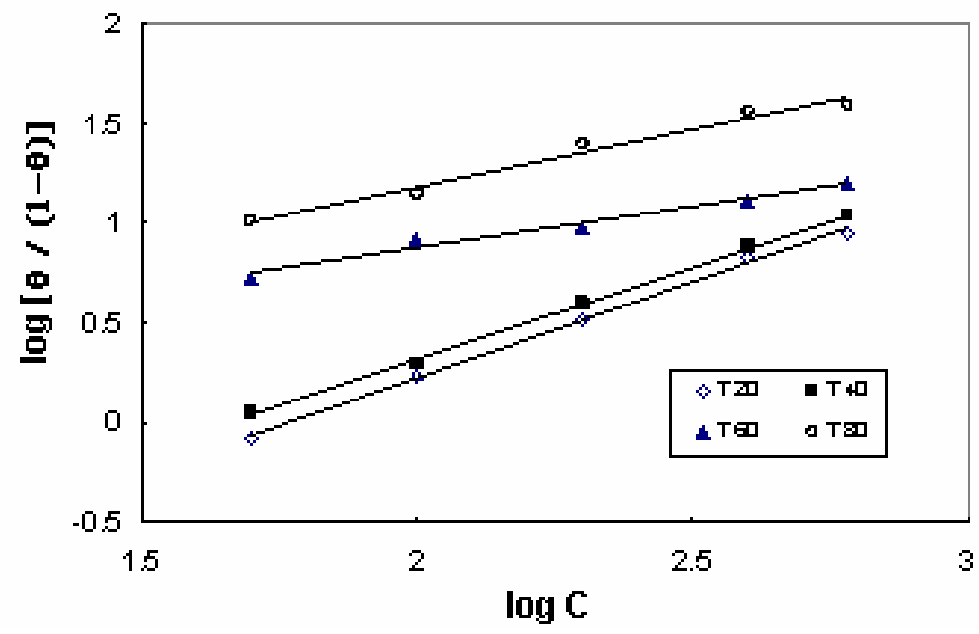

Figure 2. Isotherms of different tween compounds.

The following equations describe the Langmuir adsorption isotherm [14]:

$$
\log [\theta / 1-\theta]=\log \mathrm{C}+\log \mathrm{k}
$$

where

$$
\log k=-1.74-\left[\Delta \mathrm{G}^{\mathrm{o}} / 2.303 \mathrm{RT}\right]
$$

Thus, the values of free energy of adsorption $\left(\Delta \mathrm{G}^{0}\right)$ are calculated using these equations. It was found that $\Delta \mathrm{G}^{0}$ values are -164 and -1041 joule for T40 and $\mathrm{T} 60$, respectively. On the other hand, $\Delta \mathrm{G}^{\mathrm{o}}$ values for $\mathrm{T} 60$ and $\mathrm{T} 80$ cannot be determined by equations 3 and 4 because both the two compounds deviate from Langmuir adsorption behavior and their adsorption energies are function of $\theta$. It is very important to mention here that the calculated $\Delta \mathrm{G}^{0}$ values are not related to any standard weight of the tween compounds, such as mole. This is because the calculated values are based on the data extracted from Fig. 2, where the 
concentration is expressed by pmm unit, whereas the value of $\mathrm{R}$ in the equation is expressed by cal $/$ mole. Thus, the obtained values of $\Delta G^{\circ}$ do not refer to the actual values of the free energies of adsorption. However, these values could be used for relative comparison between different tween compounds. The negative $\Delta \mathrm{G}^{\mathrm{o}}$ values suggest that the adsorption process is spontaneous. The observed deviation of T60 and T80 from Langmuir behavior may be due to the existence of interaction forces among their adsorbed molecules.

\section{Cyclic voltammetry}

Fig. 3 represents the cyclic voltammetric curves of nickel, in $1.0 \mathrm{M} \mathrm{H}_{2} \mathrm{SO}_{4}$ solutions containing different concentrations of tween 80 , traced at scanning rate (v) of $10 \mathrm{mV} / \mathrm{sec}$, between hydrogen and oxygen evolution potentials. Similar curves were also obtained for the rest of tween compounds but not shown here. Inspection of Fig. 3 reveals that there is only one large anodic peak and no peaks could be observed in the cathodic loop. Some authors [6, 15-17] reported that nickel gives a small anodic peak in addition to the large one and others [11] recorded a very small cathodic peak. However, we have recorded the appearance of a small anodic peak by using voltage scanning rate smaller than $10 \mathrm{mV} / \mathrm{sec}$. It was reported that the large anodic peak corresponds to the oxidation of nickel to nickel hydroxide and/or oxide. Thus, this peak is responsible for the passivation of nickel in sulfuric acid solution. So, the dissolution of nickel takes place at its potential and results in the formation of the passive layer, which retards the rate of nickel corrosion in sulfuric acid. The presence of such unique dissolution peak makes it possible to use its current to represent the corrosion rate of nickel, and its potential as the corrosion potential. Moreover, the inhibition efficiencies of different tween compounds could be calculated using these parameters.

Inspection of Fig. 3 reveals that the presence of tween 80 in the acid solution results in a large decrease of the anodic peak current. This behavior is in contrast with those recorded for other inhibitors $[6,11]$, which increase the anodic peak current upon their addition. It was claimed that these compounds enhance the passivation current and consequently lead to more protection of nickel against 
corrosion process. However, it could be observed in Fig. 3 that the addition of tween decreases both the current of the anodic peak and of the plateau (passive current). This behavior leads to the conclusion that the adsorbed tween molecules prevent the dissolution of nickel and act as a passive layer better than the oxide one. Thus, while other compounds act through enhancement of nickel dissolution and forming a thicker passive oxide layer, tween compounds act through adsorption on nickel surface preventing directly the nickel dissolution. This is the reason of the observed higher inhibition efficiencies of tween compounds than those recorded for the other compounds.

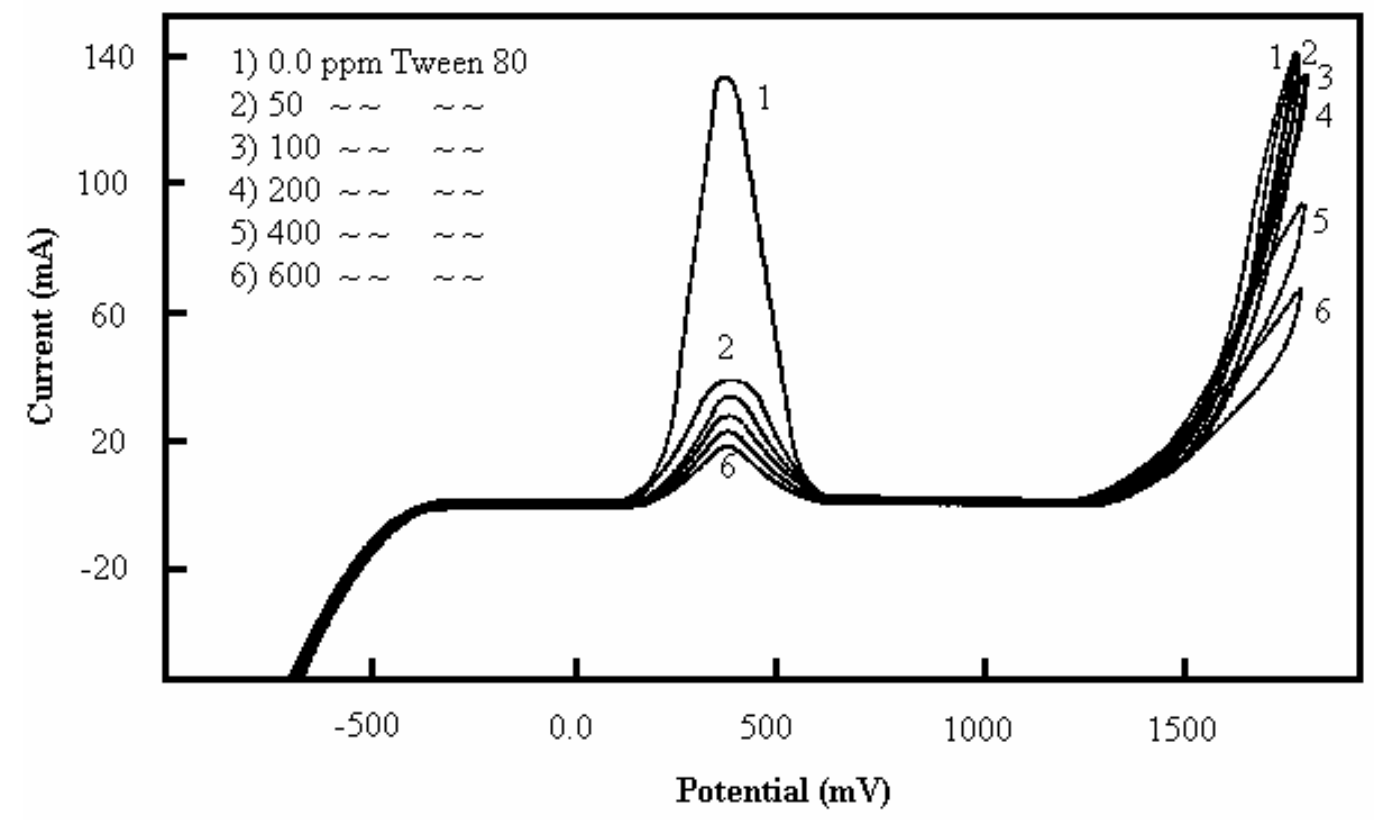

Figure 3. Cyclic voltammograms of nickel in $1.0 \mathrm{MH}_{2} \mathrm{SO}_{4}$ solutions containing different concentrations of tween $80 . v=10 \mathrm{mV} / \mathrm{sec}$.

Potentials and currents of the anodic peak, in $1.0 \mathrm{H}_{2} \mathrm{SO}_{4}$ solutions containing different concentrations of tween compounds, as well as the inhibition efficiencies calculated from the peak current, are represented in Table 3. Inspection of Table 3 reveals that the peak potential, which refers to corrosion potential, is shifted toward more noble direction in the presence of tween compounds. The magnitude of potential shift increases as the tween concentration is increased. This behavior is in agreement with that observed in 
the potentiostatic technique, although the difference in the absolute values of the potential. On the other hand, the peak current is greatly reduced as a result of addition of tween compounds, indicating the inhibitive effect of these compounds. The values of inhibition efficiencies, calculated from the cyclic voltammetry technique, are comparable with those calculated using weight loss and potentiostatic techniques.

Table 3. Electrochemical parameters of nickel corrosion in free and inhibited $1.0 \mathrm{M}$ $\mathrm{H}_{2} \mathrm{SO}_{4}$ solutions as revealed from cyclic voltammetry technique $(v=10 \mathrm{mV} / \mathrm{sec})$.

\begin{tabular}{cccc}
\hline $\mathbf{1 . 0} \mathbf{M ~ H}_{\mathbf{2}} \mathbf{S O}_{\mathbf{4}}+\ldots$ & $\mathbf{E}_{\mathbf{p}} / \mathbf{~} \mathbf{W}$ & $\mathbf{I}_{\mathbf{p}} / \mathbf{m A}$ & $\mathbf{I E} \%$ \\
\hline $\mathbf{0 . 0} \mathbf{~ p p m ~ ( t w e e n ~ 2 0 )}$ & $\mathbf{2 9 0}$ & $\mathbf{1 3 5}$ & ----- \\
50 & 299 & 40 & 70.37 \\
100 & 315 & 34 & 74.81 \\
200 & 322 & 26 & 80.74 \\
400 & 335 & 22 & 83.70 \\
600 & 348 & 18 & 86.66 \\
\hline $\mathbf{0 . 0}$ ppm (tween 40) & $\mathbf{2 9 0}$ & $\mathbf{1 3 5}$ & ---- \\
50 & 305 & 35 & 74.07 \\
100 & 318 & 30 & 77.77 \\
200 & 331 & 23 & 82.96 \\
400 & 342 & 19 & 85.92 \\
600 & 354 & 16 & 88.12 \\
\hline $\mathbf{0 . 0}$ ppm (tween 60) & $\mathbf{2 9 0}$ & $\mathbf{1 3 5}$ & ---- \\
50 & 308 & 27 & 80.00 \\
100 & 320 & 20 & 85.15 \\
200 & 335 & 15 & 88.88 \\
400 & 350 & 12 & 91.11 \\
600 & 361 & 10 & 92.59 \\
\hline $\mathbf{0 . 0}$ ppm (tween 80) & $\mathbf{2 9 0}$ & $\mathbf{1 3 5}$ & ---- \\
50 & 315 & 18 & 86.66 \\
100 & 338 & 12 & 91.11 \\
200 & 351 & 8 & 94.07 \\
400 & 365 & 6 & 95.55 \\
600 & 378 & 5 & 96.22 \\
\hline & & & \\
\hline
\end{tabular}

\section{Conclusions}

1- The tested tween compounds establish a very good inhibition for nickel corrosion in sulfuric acid solution.

2- Tween compounds inhibit the nickel corrosion by adsorption on its surface and act better than the passive oxide film. 
3- The inhibition efficiency increases as the length of the tween hydrocarbon chain is increased.

4- The inhibition efficiencies of the tested tween compounds increase with increasing of their concentrations.

\section{References}

1. J.R. Kish, M.B. Ives, J.R. Kodda, J. Electrochem. Soc. 147 (2000) 3637.

2. M. Keddam, H. Takenouti, N. Yu, J. Electrochem. Soc. 132 (1985) 2561.

3. T. Ohtsuka, K.E. Heusler, J. Electroanal. Chem. 102 (1979) 175.

4. N. Sato, K. Kudo, Electrochim. Acta 19 (1974) 461.

5. G. Gilli, P. Borea, F. Zucchi, G. Trabanelli, Corros. Sci. 13 (1973) 585.

6. A.A. Aksut, S. Bilgic, Corros. Sci. 33 (1992) 379.

7. E. Khamis, F. Bellucci, R.M. Latanision, E.S.H. El-Ashry, Corrosion 47 (1991) 677.

8. S.M. Reshetnikov, Port. Met. 14 (1978) 491.

9. V. Sastry, R. Packwood, Werkst. Korros. 38 (1987) 77.

10. A. Frignani, C. Monticelli, G. Trabanelli, Br. Corros. J. 33 (1998) 71.

11. C.F. Zinola, A.H. Castro Luna, Corros. Sci. 37 (1995) 1919.

12. K. Bajpai, G. Singh, Bull. Electrochem. 16 (2000) 241.

13. P.B. Mathur, T. Vasudevan, Corrosion 38 (1982) 17.

14. T.P. Hoar, R.D. Haliday, J. Appl. Chem. 3 (1953) 502.

15. T.S. De Gromoboy, L.L. Shreir, Electrochim. Acta 11 (1966) 895.

16. J.R. Vilche, A.J. Arvia, Corros. Sci. 18 (1978) 441.

17. V.H. Hluchan, B.L. Wheeler, A.J. Arvia, Corros. Sci. 20 (1980) 563. 